\title{
CREACIÓN Y FORTALECIMIENTO DE LAS MIPYMES EN EL SECTOR CONFECCIONES DEL ÁREA METROPOLITANA CENTRO OCCIDENTE DE PEREIRA
}

Jhoao Paolo Barco Ortega*

\section{Resumen}

Pereira durante varios años ha estado entre los diez primeros lugar de las ciudades más competitivas a nivel nacional, gracias a las estrategias de competitividad y su responsabilidad social empresarial. Sin embargo, no ha presentado un ascenso debido a la falta de inclusión de otros factores; por tanto, con este proyecto se buscó observar e identificar cuáles eran los componentes faltantes requeridos para mejorar su eficiencia.

Para evidenciar, recopilar y crear nuevas estrategias y modelos que posibiliten la creación y fortalecimiento de las mipymes en el sector confecciones en el Área Metropolitana Centro Occidente de Pereira, en busca de una mayor rentabilidad económica, se indagó cuáles eran las diferentes acciones que fomentaban los alcaldes locales como ayuda a las mipymes en las que el sector confecciones puede sacar un mayor provecho si son puestas en marcha. 


\section{Introducción}

En la actualidad, las micro, pequeñas y medianas empresas (mipymes) desempeñan un papel fundamental en la economía del mundo, representando casi la totalidad de las empresas existentes a nivel global. En Colombia, las mipymes han ido creciendo porcentualmente; para el 2015, este conjunto de empresas representaba para el país el $96 \%$. Estas empresas generan más del $44,7 \%$ del producto interno bruto (PIB) a escala nacional. Asimismo, el departamento de Risaralda se ha posicionado en el país como uno de los más competitivos. No obstante, según la revista Dinero (2017), presentan un retroceso debido a su poco nivel de competitividad, factor clave para la generación de producción innovadora.

Por consiguiente, García (2016) dice que las pymes deben enfrentarse a un mercado cada vez más exigente, con creatividad e innovación $y$, a la vez, deben buscar clientes nacionales e internacionales. De esta forma, el Eje Cafetero, específicamente en la ciudad de Pereira, es una buena muestra de que poco a poco se van implementando esas estrategias. Sin embargo, no se puede dejar de reconocer que hay otros factores que no son tan fuertes actualmente y que explicaría la baja participación de las pymes en las exportaciones.

Por ello, es indispensable mejorar la eficiencia de las mipymes, mediante nuevas innovaciones como lo ha sido el cambio tecnológico, la Responsabilidad Social Empresarial y la aplicación de modelos de evaluación de la gestión del conocimiento para empresas, lo que ha brindado el incremento en procesos, productos y servicios con intereses sociales, ecológicos y económicos de la acción empresarial.

El Gobierno colombiano ha implementado un plan de competitividad basado en la Responsabilidad Social Empresarial (RSE), cuyo objeto es generar estrategias, en un plazo de tiempo determinado, que ayuden a su mejor funcionamiento. En el 2017, Pereira implementó este plan, el cual le permitió quedar en el $4^{\circ}$ puesto entre las ciudades más competitivas a nivel nacional. Sin embargo, no ha logrado mejorar esta posición, dado que no ha implementado hasta ahora otros factores de innovación en sus empresas.

Por lo cual, es necesario determinar los factores que influyen en la creación y fortalecimiento de las mipymes del sector confecciones en el Área Metropolitana Centro Occidente de Pereira, y así lograr evidenciar los diferentes puntos de vista en cuanto a las actividades de una micro, pequeña y mediana empresa y su forma de trabajar; dando así un apoyo para aquellos negocios de confecciones que afronten tanto situaciones en que quieran aumentar su nivel de efectividad, como momentos en que se enfrentan a fuertes obstáculos en la medida que la competencia aumenta.

\section{Materiales y métodos}

Las fuentes de procedencia que se utilizarán para desarrollar la investigación, provienen de diferentes medios. Una de ellas son las bases de datos como ar- 
tículos, teorías y libros en internet que brindaron todo el soporte base para entender a fondo el tema que se iba a tratar, para conocer su historia, su procedencia y qué tan influyente ha sido; después de tener un contexto amplio de dichos datos se utilizarán otras fuentes, como la de datos de las diferentes Cámaras de Comercio de Pereira y Dosquebradas, para así obtener una información más realista y puntual acerca de las mipymes de confección.

La investigación realizada es de tipo cuantitativa observacional analítica, pues con esta es posible manejar y trabajar datos medibles, permitiendo una aproximación más sistemática y analítica, para así observar los procesos por los cuales se han creado, desarrollado y progresado las mipymes de confección en los últimos años en el ámbito de la competitividad e innovación.

La población evaluada será de las mipymes en el sector confecciones de las que se busca recolectar información para su respectivo análisis. Dicha recolección de datos se realizará en el Área Metropolitana Centro Occidente, puesto que en los últimos años se ha posicionado a nivel nacional como una de las mejores ciudades para crear este tipo de empresas; además, la cantidad de empresas de este tipo ha crecido moderadamente en la ciudad.

\section{Resultados esperados}

Con esta investigación se espera determinar los factores que contribuyen al fortalecimiento de las mipymes para el sector confecciones, aportando nuevos conceptos que permitan un óptimo desarrollo, con niveles altos de competitividad, teniendo como base la responsabilidad social empresarial y el plan regional de competitividad de Risaralda.

\section{Conclusión parcial}

Puede decirse que las mipymes son el "motor" de la economía del mundo, pues representan casi la totalidad de las empresas existentes a nivel global. En Colombia, estas empresas siguen enfrentándose a retos muy grandes, como lo es el mercado cada vez más exigente; además del retroceso frecuente desde años anteriores, esto está causando inconvenientes relacionados con la competitividad frente a otros mercados. El gobierno de la región se encuentra comprometido con el crecimiento de estas y se ve reflejado en la cantidad de programas que ha diseñado tanto en Pereira como en Dosquebradas

Pereira ha tenido un aumento considerable y positivo. En el 2016 se encontraban constituidas 3404 mipymes y para el 2019 ya son 6350 , lo que significa que el gobierno sí ha cumplido con las políticas de empuje. Por otro lado, Dosquebradas cada vez más ha implementado prácticas de apoyo a la empresa local; sin embargo, sus resultados no han sido tan buenos en la constitución de empresas.

\section{Referencias}

1. Cámara de Comercio de Pereira. (2019). Serie estudios económicos. Pereira. 
2. Cámara de Comercio de Pereira. (2019). Reporte de inversión durante el tercer trimestre de 2019. Pereira.

3. Cámara de Comercio de Pereira. (2018). Reporte de inversión durante el tercer trimestre de 2018. Pereira.

4. Cámara de Comercio de Pereira. (2018). Categorías de empresas de acuerdo a su constitución. Pereira.

5. Cámara de Comercio de Pereira. (2018). Encuesta Ritmo Empresarial, segundo semestre de 2018. Pereira.

6. Cámara de Comercio de Pereira. (2017). Reporte económico. Pereira.

7. García, M. L. (2012). Una propuesta para la determinación. Scielo.
8. Lemus, M. V. (s.f.). Confecciones tejen el futuro de Risaralda. https://www. camarapereira.org.co/es/confecciones-tejen-el-futuro-de-risaralda-EV2144

9. Montoya, A., Montoya, I., \& Castellanos, Ó. (2010). Situación de la competitividad de las pymes: elementos actuales $y$ retos. https://www.redalyc.org/articulo. oa?id=180315651012

10. Porter, M. (s.f.). Ser competitivo. Deusto.

11. Revista Dinero. (2016). Mipymes generan alrededor del $67 \%$ del empleo en Colombia. 